\title{
Thermal Comfort in Air-Conditioned Space by Desiccant Cooling
}

\author{
Joon Ahn', Hoyup Choi ${ }^{1}$ \\ ${ }^{1}$ School of Mechanical Engineering, Kookmin University \\ Seoul, Korea \\ jahn@kookmin.ac.kr
}

\begin{abstract}
A series of field tests on hybrid desiccant cooling systems were conducted at a residential house air-conditioned by a desiccant cooling system driven by district heating. The performance of the cooling system, i.e. cooling capacity and COP (Coefficient of Performance), were evaluated from measured data and its variation subject to outdoor conditions was analyzed. Its performance in a residential environment were proved with typical Korean environment. However, economical and functional merits need to be verified to be competitive in the commercial market. Thermal comfort is one of the strong points of desiccant cooling system, since it has ventilation and dehumidification functions. To quantify thermal comfort, indices such as PMV and PPD have been evaluated for the airconditioned space based on measured and CFD data. The results show that supply geometry needs to be improved to eliminate discomfort area.
\end{abstract}

Keywords: Hybrid desiccant cooling system, Thermal comfort, PMV (Predicted mean vote), CFD.

\section{Introduction}

Recently, energy saving has become a hot topic, and various air conditioning systems having high energy efficiency are being developed. These systems must meet the energy saving performance and the thermal comfort of indoor residents, which is the role of the air conditioning system. In addition, the importance of comfortable indoor environment is increasingly emphasized by improvement of living standard.

The thermal environment indices of the elements for evaluating the indoor environment, PMV (Predicted mean vote) is typical. It is designed to evaluate how the human body feels the thermal sensation. PMV is quantifying the response to thermal environment of the crowd of people. And this refers to the overall thermal comfort of the human body feels in light

(a)

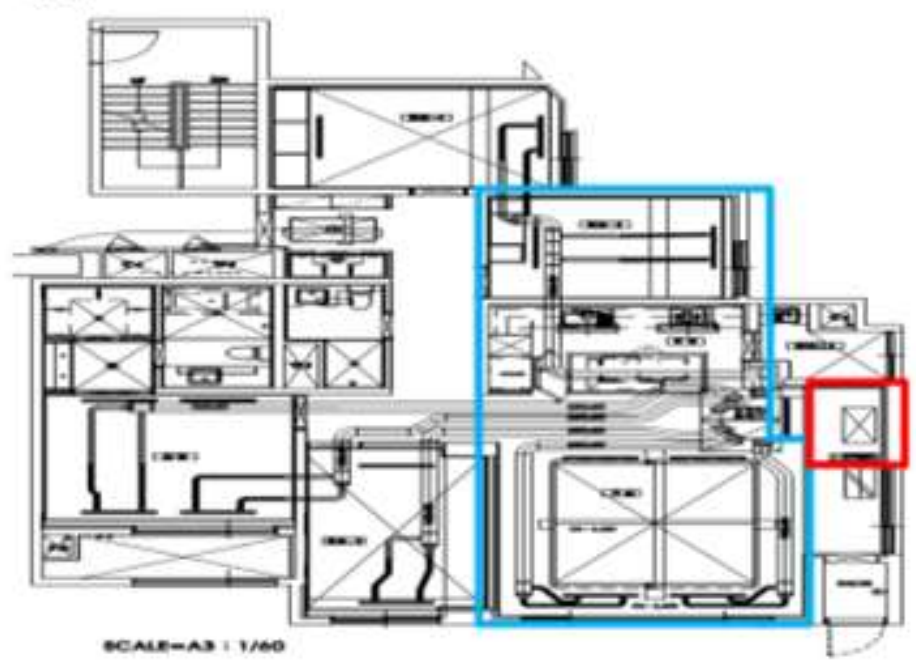

(b)

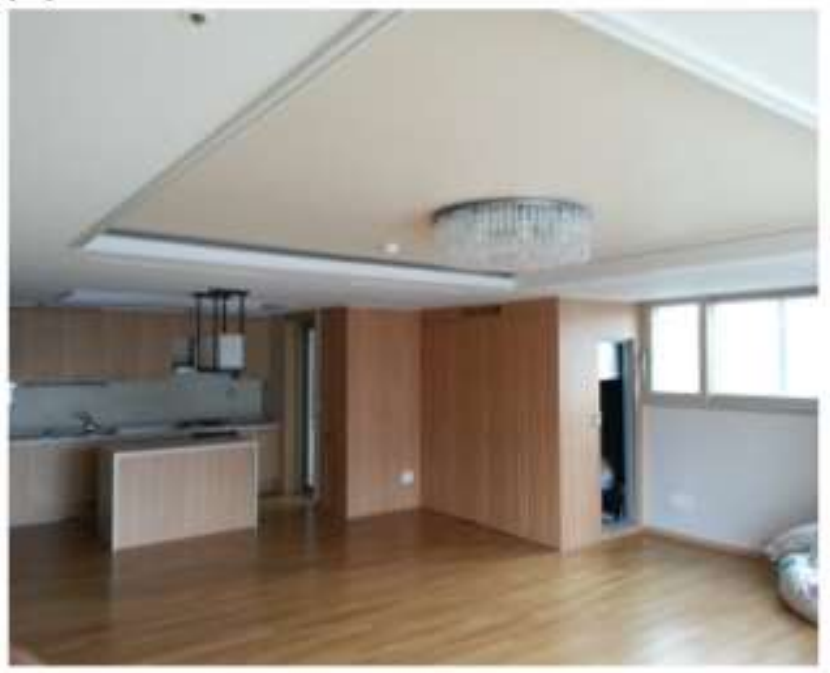

Fig. 1: Field test site; (a) floor plan; (b) photograph. 
of metabolic rate of the human body, the thermal resistance of the clothing, the dry-bulb temperature, the mean radiant temperature, air flow, humidity, etc.

Table 1: Specifications of the desiccant cooling system.

\begin{tabular}{|c|c|}
\hline Cooling capacity $(\mathrm{kW})$ & 7.0 \\
\hline Regeneration heat $(\mathrm{kW})$ & 4.46 \\
\hline Electrical power consumption $(\mathrm{kW})$ & 1.27 \\
\hline
\end{tabular}

In this study, we evaluated thermal comfort using the PMV at a residential house air-conditioned by hybrid desiccant cooling system with a ventilation and dehumidification functions.

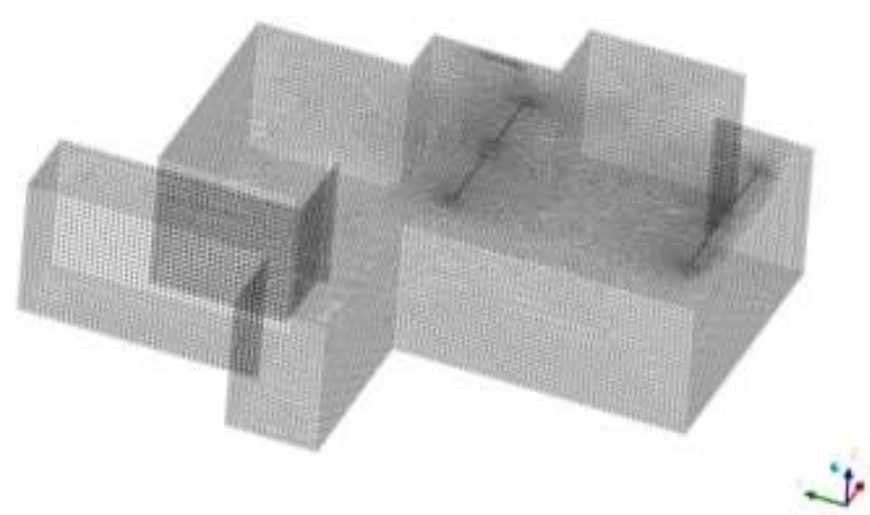

Fig. 2: Computational domain for CFD.

Table 2: Boundary conditions for CFD.

\begin{tabular}{|c|c|}
\hline Inlet & Velocity: $4.7 \mathrm{~m} / \mathrm{s}$, Temperature: $291.3 \mathrm{~K}$ \\
\hline Outlet & Pressure outlet \\
\hline Wall & Standard wall function, Window: $145 \mathrm{~W} / \mathrm{m} 2$, Other walls: $300 \mathrm{~K}$ \\
\hline Turbulence model & Realizable $k-\varepsilon$ model \\
\hline
\end{tabular}

\section{Experiment and Analysis Procedure}

We have conducted experiments in a residential apartment with cooling space of $126 \mathrm{~m}^{2}$ in Giheung gu, Yongin City, Korea. The cooling capacity of installed desiccant cooling system is $7.0 \mathrm{~kW}$, and the major specifications are summarized in Table1. The measurement point is the kitchen and dining room and living room. And the average outdoor temperature and humidity during the period of the experiment are $29.7^{\circ} \mathrm{C}$ and $62 \%$, respectively.

In this study, we used the data of the indoor temperature and humidity throughout the experiment in a residential house. We used a measuring device named IES-200 made in Shibata Scientific Technology and measured the indoor temperature, glove temperature and relative humidity. 
We obtained the air velocity through CFD because the air velocity in a residential house is lower than range $(0.2 \sim 2.0$ $\mathrm{m} / \mathrm{s}$ ) of accurate measurement. And MRT (Mean radiant temperature) was calculated by the air velocity from glove temperature and data from CFD. Figure 2 shows the modeling of the cooling space for the numerical simulation.

Numerical Analysis of boundary conditions are shown in Table 2 . We set $4.7 \mathrm{~m} / \mathrm{s}$ velocity and $18{ }^{\circ} \mathrm{C}$ temperature conditions at the outlet of the air-conditioner. The flow rate was calculated as the average of the values measured separately separately with regular intervals at the discharge port. Walls of the room were normally set at isothermal conditions. If the the wall includes window, we set the constant heat flux. For this case, the heat flux value is set at $145 \mathrm{~W} / \mathrm{m}^{2}$.

(a)

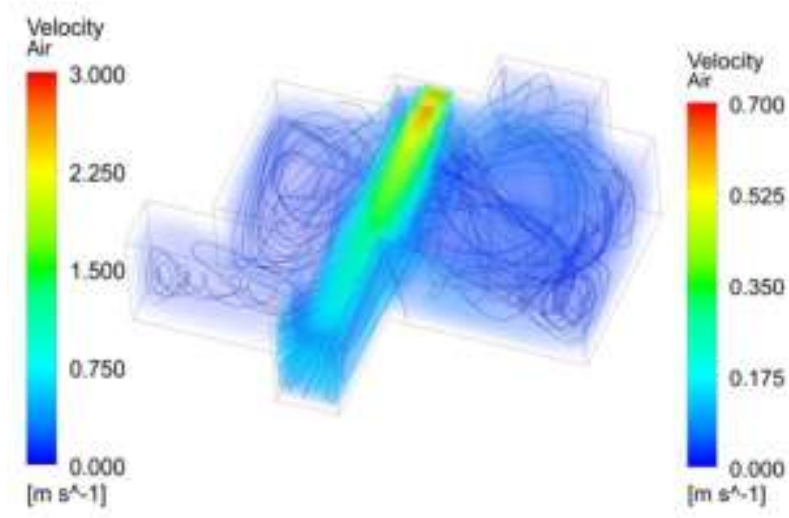

(b)



(c)

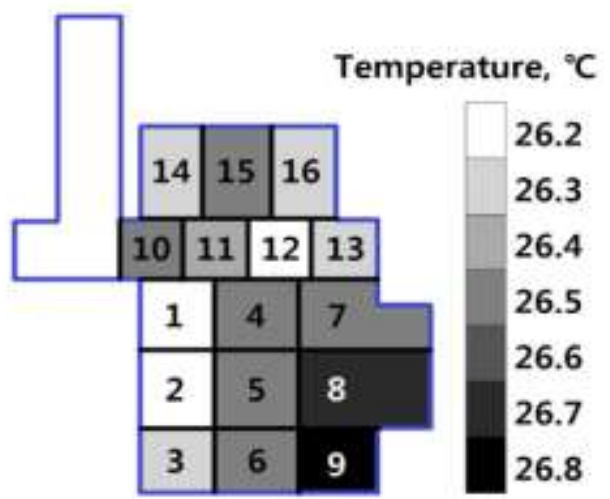

Fig. 3: Flow and thermal fields inside the air-conditioned space; (a) Streamlines from CFD; (b) Velocity contours from CFD at the height of $0.5 \mathrm{~m}$; (c) Temperature at the height of $0.5 \mathrm{~m}$.

We used PMV index to evaluate thermal comfort in ISO Standard 7330 [1]. The average thermal sensation response of a large number of subjects, using the ASHRAE thermal sensation scale, is called the predicted mean vote (PMV). PMV indicated that the sensation of thermal comfort was most significantly determined by narrow ranges of skin temperature and sweat evaporation rate depending on activity level (More active people were comfortable at low skin temperatures and higher evaporation rates.) by combining this information with the thermal energy balance equations above, they developed a set of correlations giving the PMV as a function of six variables: air temperature, mean radiant temperature, air velocity, air humidity, clothing resistance, and activity level. The equation for obtaining PMV is as follows.

$$
\begin{gathered}
\text { PMV }=\left(0.303 \mathrm{e}^{-0.036 \mathrm{M}}+0.028\right)\left[(M-W)-3.05 \cdot 10^{-3}\left\{5733-6.99(M-W)-P_{a}\right\}\right. \\
-0.42\{(M-W)-58.15\}-1.7 \cdot 10^{-5} M\left(5867-P_{a}\right)-0.0014 M\left(34-T_{a}\right)-3.96 \\
\left.\cdot 10^{-18} f_{c l}\left\{\left(T_{c l}+273\right)^{4}-\left(\bar{T}_{r}+273\right)^{4}\right\}-f_{c l} h_{c}\left(T_{c l}-T_{a}\right)\right] \\
2.38\left(T_{c l}-T_{a}\right)^{0.25}\left(\text { Value of } 2.38\left(T_{c l}-T_{a}\right)^{0.25}>12.1 \sqrt{V_{a r}}\right) \\
12.1 \sqrt{V_{a r}}\left(\text { Value of } 2.38\left(T_{c l}-T_{a}\right)^{0.25}<12.1 \sqrt{V_{a r}}\right) \\
h_{c}=\begin{array}{l} 
\\
T_{c l}=35.7-0.028(M-W) \\
-0.155 l_{c}\left[3.96 \cdot 10^{-18} f_{c l}\left\{\left(T_{c l}+273\right)^{4}-\left(\bar{T}_{r}+273\right)^{4}\right\}+f_{c l} h_{c}\left(T_{c l}-T_{a}\right)\right] \\
f_{c l}=1.00+0.2 l_{c l}\left(\text { Value of } l_{c l}<0.5 c l o\right) \\
1.05+0.1 l_{c l}\left(\text { Value of } l_{c l}>0.5 c l o\right)
\end{array}
\end{gathered}
$$


In order to calculate the PMV, body metabolism was $1.0 \mathrm{mt}\left(58.1 \mathrm{~W} / \mathrm{m}^{2}\right)$, which is a general resting state, and 0.5 clo $\left(0.09 \mathrm{~m} 2{ }^{\circ} \mathrm{C} / \mathrm{W}\right)$ was used as the garment condition.

\section{Results and Discussion}

CFD and measured data are shown in Fig. 3. Fig. 3(a) shows streamlines of indoor air. Most of the cooling air passing through the dining table could not flow into the kitchen and the living room, so it was stuck on the wall opposite to the conditioned air supply. This is probably due to the pressure drop of the cooling air and the influence of the indoor structure.

As shown in Fig. 3(b), the measured temperatures are not significantly different at each point. However, it is judged that the reason for the highest temperature in 8th and 9th is due to the solar radiation through the window.

Figure 3(c) shows the airflow velocity at the height of $0.5 \mathrm{~m}$ in the XY plane. Airflow speeds are clearly distinguished by kitchen, dining room, and living room. At the dining room, the air velocity was higher than that of the kitchen and the living room, which was directly influenced by the cooling air from the supply

Table 3: Air conditions and thermal comfort at 3 measuring points.

\begin{tabular}{|c|c|c|c|c|c|c|}
\hline \multirow{2}{*}{ Point } & \multirow{2}{*}{ Temperature } & \multirow{2}{*}{$\begin{array}{c}\text { Relative } \\
\text { humidity }\end{array}$} & \multirow{2}{*}{ Velocity } & \multicolumn{2}{|c|}{ Radiation temperature } & \multirow{2}{*}{ PMV } \\
\cline { 5 - 6 } & & & Glove & Radiation & \\
\hline Living room & $26.5^{\circ} \mathrm{C}$ & $57.2 \%$ & $0.15 \mathrm{~m} / \mathrm{s}$ & $29.5^{\circ} \mathrm{C}$ & $32.3^{\circ} \mathrm{C}$ & 1.20 \\
\hline Dining room & $26.4^{\circ} \mathrm{C}$ & $57.6 \%$ & $0.45 \mathrm{~m} / \mathrm{s}$ & $29.1^{\circ} \mathrm{C}$ & $33.3^{\circ} \mathrm{C}$ & 0.68 \\
\hline Kitchen & $26.4^{\circ} \mathrm{C}$ & $57.8 \%$ & $0.09 \mathrm{~m} / \mathrm{s}$ & $29.2^{\circ} \mathrm{C}$ & $31.2^{\circ} \mathrm{C}$ & 1.22 \\
\hline Total & $26.4^{\circ} \mathrm{C}$ & $57.4 \%$ & $0.26 \mathrm{~m} / \mathrm{s}$ & $29.3^{\circ} \mathrm{C}$ & $32.8^{\circ} \mathrm{C}$ & 0.97 \\
\hline
\end{tabular}

Table 3 shows the measured data and the results of the analysis. The overall PMV value is close to 1, which is somewhat warm. At the dining room, the PMV value was 0.68 , which was a comfortable space, but the PMV values $(1.2,1.22)$ in the living room and kitchen were higher than 1.The reason why the PMV value of the living room and the

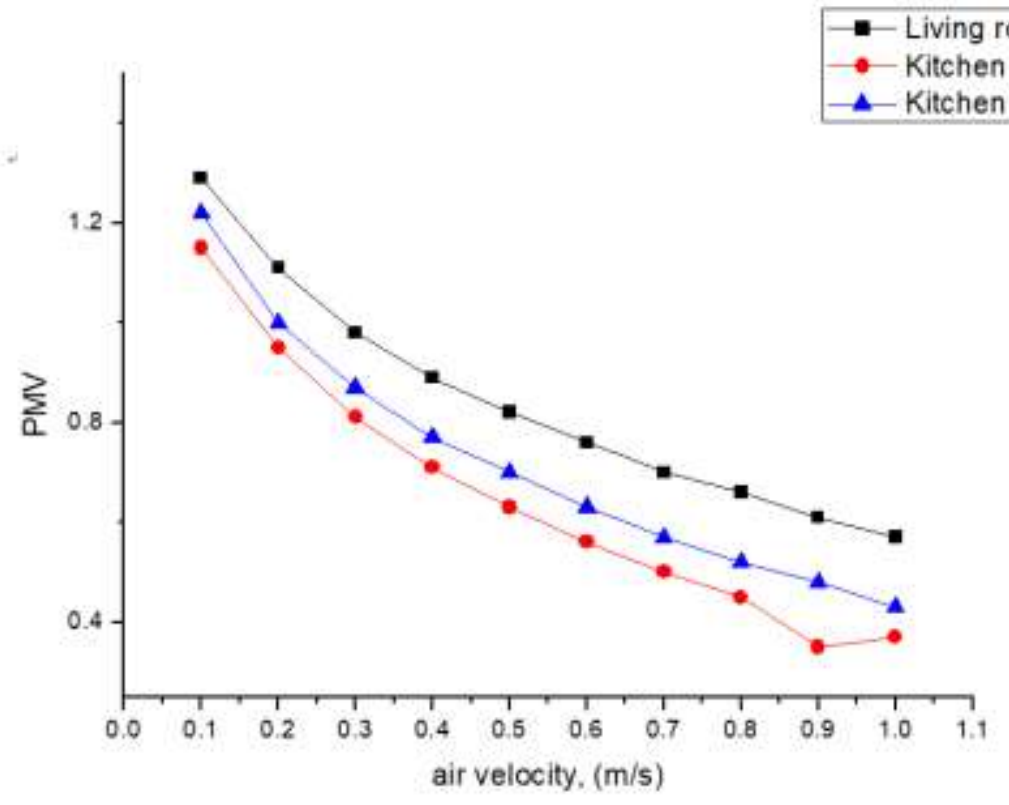

Fig. 4: Thermal comfort according to air velocity. 
kitchen is high is as shown in Fig. 3 (a) because the air velocity is significantly lower than one measured at the dining table. This seems to be the phenomenon that the cooling air from the discharge port can not circulate due to the pressure drop and stagnates on the opposite wall.

Figure 4 shows the change of PMV according to the air velocity in each space. The horizontal axis represents the airflow airflow velocity in the room and the vertical axis represents the PMV value in each cooling space. It is shown that each space space has lower PMV value when the air velocity is increased under the same conditions. It is expected that the total PMV PMV value can be lowered by changing the airflow speed of the living room and the kitchen from 0.2 to $0.4 \mathrm{~m} / \mathrm{s}$, and the PMV value will be constant in the whole space. However, increasing the air velocities of the living room and the kitchen should reduce the air velocity of the table and increase the PMV value, so that the appropriate airflow rate $(0.3 \mathrm{~m} / \mathrm{s}$ or higher) should be maintained.

\section{Conclusion}

In order to increase the airflow speed of the living room and the kitchen, it is possible to propose a method of increasing the jet angle of the air conditioner outlet to the left or right or increasing the air velocity of the ceiling outlet.

In addition to research on future improvement of the supply geometry, comprehensive thermal comfort evaluation will be carried out taking into consideration the body metabolism and wear state, and heat generated by the household devices. Also, considering the dehumidifying effect, which is an advantage of the hybrid dehumidification cooling system, a comparative study of thermal comfort with the existing electric air conditioner will be carried out.

\section{References}

[1] ASHRAE, Fundamentals Handbook. Chapter 8, 1995.

[2] P. P. Fanger, Thermal Comfort analysis and Application in Environmental Engineering. Copenhagen, Denmark: Danish Technical Press, 1970.

[3] ISO Standard 7330, 1998.

[4] INNOVA AirTech Instruments, Thermal Comfort, 2003.

[5] T. H. Huehn, J. W., Ramsey and J. L. Threlkeld, Thermal Environmental Engineering. Prentice Hall, 1998. 